\title{
Neurocysticercosis as a probable risk factor for hippocampal sclerosis
}

\author{
Neurocisticercose como provável fator de risco para esclerose hipocampal \\ Gagandeep Singh ${ }^{1,2}$, Josemir W. Sander ${ }^{2,3}$
}

\begin{abstract}
Neurocysticercosis is one of the most common risk factors for epilepsy but its association with drug-resistant epilepsy remains uncertain. Conjectures of an association with drug-resistant epilepsy have been fueled by reports of an association between calcific neurocysticercosis lesions (CNL) and hippocampal sclerosis (HS) from specialized epilepsy centers in Taenia solium-endemic regions. The debate arising from these reports is whether the association is causal. Evidence for the association is not high quality but sufficiently persuasive to merit further investigation with longitudinal imaging studies in population-based samples from geographically-diverse regions. The other controversial point is the choice of a surgical approach for drug-resistant epilepsy associated with CNL-HS. Three approaches have been described: standard anteromesial temporal lobectomy, lesionectomy involving a CNL alone and lesionectomy with anteromesial temporal lobectomy (for dual pathology); reports of the latter two approaches are limited. Presurgical evaluation should consider possibilities of delineating the epileptogenic zone/s in accordance with all three approaches.
\end{abstract}

Keywords: Drug resistant epilepsy; neurocysticercosis; epilepsy.

\section{RESUMO}

A neurocisticercose é um dos mais comuns fatores de risco para a epilepsia, mas sua associação com a epilepsia resistente a medicamentos (DRE) permanece incerta. Conjecturas de uma associação com a DRE têm sido alimentadas por relatos de uma associação entre lesões de neurocisticercose calcária (CNL) e esclerose hipocampal (HS) de centros especializados em epilepsia em regiões endêmicas de Taenia solium. O debate que surge desses relatórios é se a associação é causal. Se bem as evidências para a associação não são de alta qualidade, são suficientemente persuasivas para merecer mais investigação com estudos longitudinais de imagens em amostras de base populacional de regiões geograficamente diversas. O outro ponto controverso é a escolha da abordagem cirúrgica para a DRE associada à CNL-HS. Três abordagens têm sido descritas: lobectomia temporal ântero-mesial padrão, lesionectomia envolvendo apenas CNL e lesionectomia com lobectomia temporal ântero-mesial (para patologia dupla); os relatórios das duas últimas abordagens são limitados. A avaliação pré-cirúrgica deve considerar as possibilidades de delinear a (s) zona (s) epileptogênica (s) de acordo com as três abordagens.

Palavras-chave: Epilepsia resistente a medicamentos; neurocisticercose; epilepsia.

Human brain infestation with the larval stage of the tapeworm Taenia solium, known as neurocysticercosis (NCC), is endemic in many low-income countries but is also recognized in high-income countries (e.g., the United States) ${ }^{1}$. It is estimated that between two and eight million people worldwide have $\mathrm{NCC}^{2}$. Population studies in T. solium-endemic regions of South-Central America, India and parts of Africa have identified NCC as the putative risk factor in roughly one third of epilepsy cases ${ }^{3,4,5,6}$.

Seizures are the most common clinical presentation and are estimated to occur in up to $80 \%$ of people with symptomatic $\mathrm{NCC}^{7}$. Follow-up studies have suggested that the prognosis for seizure control is good overall, though seizures might recur on antiepileptic drug withdrawal ${ }^{8,9}$. Rarely, however, NCC might be associated with difficultto-treat epilepsy ${ }^{10,11,12,13}$. The substrates underlying chronic, often drug-resistant, epilepsy are a matter of considerable speculation as well as ongoing investigation. Perilesional gliosis, seen in unconventional magnetic resonance (MR) sequences (e.g., magnetization transfer imaging) but occult in routine MR sequences, has been associated with poorly-controlled epilepsy ${ }^{13,14}$. This, however, needs to be

1Dayanand Medical College, Department of Neurology, Ludhiana, India,

${ }^{2}$ NIHR University College London Hospitals Biomedical Research Centre, UCL Queen Square Institute of Neurology, London WC1N 3BG, United Kingdom;

${ }^{3}$ Stichting Epilepsie Instellingen Nederland (SEIN), Achterweg 5, Heemstede, Netherlands.

Correspondence: Josemir W. Sander; Box 29, 33 Queen Square, London WC1N 3BG, UK; E-mail: l.sander@ucl.ac.uk

Conflict of interest: GS has received research grants from the Indian Council of Medical Research. JWS has received research funding from Eisai, GSK and UCB, personal fees from Eisai and UCB outside the submitted work.

Received 04 June 2018; Received in final form 06 August 2018; Accepted 09 August 2018. 
corroborated in larger-scale studies. If confirmed, the finding might be relevant to cases of apparent cryptogenic epilepsy with normal imaging in people with evidence of previous exposure to T. solium. An association between calcified NCC lesion(s) (CNL) and mesial temporal lobe epilepsy with hippocampal sclerosis (HS) has also been suggested, although some believe it to be purely coincidental ${ }^{15}$. Conversely, the finding of an association between NCC and HS might have a biological basis and implications for the burden of surgically-remediable epilepsy, in endemic and nonendemic regions ${ }^{16,17}$. Two issues merit consideration: (1) is the association between NCC and HS tenable and, if so, is it causal?; and (2) could the association influence the choice of surgical approaches to anti-epileptic drug-resistant epilepsy associated with CNL-HS? Here, we examine published data concerning the possible association between CNLs and HS to clarify these issues.

\section{METHODS}

\section{Search strategy}

We searched Pubmed, LILACS, CABI Abstracts and the databases of two epilepsy journals (Epilepsia and Epileptic Disorders) in September 2016 for published reports (including abstracts) of cohort, case-control and cross-sectional studies and small series and one-off case reports of an association between NCC and HS. We used the search terms, "neurocysticercosis" OR "cysticercosis" AND "temporal lobe epilepsy" OR "mesial temporal sclerosis" OR "hippocampal sclerosis". Reference lists of the retrieved articles were hand searched for further references. We reviewed abstracts published in conference proceedings published in the two epilepsy journals but were unable to obtain additional information required from most authors.

\section{Extracted information}

We extracted information on: the age of epilepsy onset; presence of, and age at, antecedent events; gender; and distribution of spikes (bilateral vs. unilateral; temporal vs. extratemporal). In those who had surgery we also extracted information on histological characteristics of the excised hippocampi; and postsurgical seizure outcome. Surgical approaches were classified as (i) temporal lobectomy (including standard anteromesial temporal lobectomy and selective amygdalohippocampectomy) alone; (ii) temporal lobectomy plus resection of a CNL (of which temporal lobectomy and resection of a temporal lobe CNL was a special subgroup); and (iii) resection of CNL alone. The number of subjects with Engel's Class I outcome following surgery in each of the three groups of surgical approaches was noted ${ }^{18}$.

\section{Analysis and statistics}

Three analyses were undertaken: (i) comparison of the reported frequency of CNLs in samples of people with HS and other epilepsies or neurological disorders; (ii) differences in various demographic and electroclinical parameters including postsurgical seizure outcome between two groups (people with HS with CNLs and those with HS alone); and (iii) concordance between the laterality of HS and CNLs on imaging studies.

\section{RESULTS}

\section{Analysis of retrieved studies}

The literature search produced 33 abstracts (Figure 1). Review of abstracts yielded five articles that were deemed not relevant to the topic, another five published reviews and two personal viewpoints/letters. Seven reports alluded to isolated cases or small case series ${ }^{10,12,19,20,21,22,23}$. Another two case reports, one describing a degenerating cysticercus (hence not CNL) in the amygdala and another with a frontal CNL but not fulfilling criteria for drug-resistant epilepsy, were reviewed but not included ${ }^{24,25}$. Data for the formal analysis were extracted mainly from the remaining studies although isolated reports were examined as well. Many of the reports were from the same center and overlapped in time. It is possible that these reports (Table 1) partly covered the same set of subjects ${ }^{11,15,16,26,27,28,29,30}$. Hence, the most relevant or recent publications with the most protracted recruitment period from each center were included for analysis) $)^{11,27,28,29}$.

\section{Association between HS and calcification}

In five hospital-based studies that reported the fraction of HS samples with CNLs, the proportion varied from $27 \%$ to $52 \%$ (median: $37 \%)^{15,16,28,30,31}$. The proportion of CNLs in corresponding samples of epilepsies other than HS at the same centers was 6-15\% (median: 14\%) ) $^{16,30,31}$.

\section{Differences between HS with CNLs and HS alone: Demographic and electro-clinical features}

A small Indian observational study reported an older age at onset of epilepsy in people with HS with CNLs in comparison with HS alone but this finding was not replicated in the larger Brazilian study ${ }^{11,27}$ (Table 2). Likewise, two Brazilian groups compared gender distribution in people who had HS with CNLs, with HS alone ${ }^{27,30}$. One group consistently reported an excess of females in people who had HS with CNLs, but this was not corroborated by an observational study from a different center in the same Brazilian state $\mathrm{e}^{15,16,27,30}$.

Some have commented on the absence of an initial precipitating illness in people who had HS with $\mathrm{CNLs}^{12,16}$. Others have found a lower frequency of an initial precipitating illness in people with HS with CNLs, compared with 


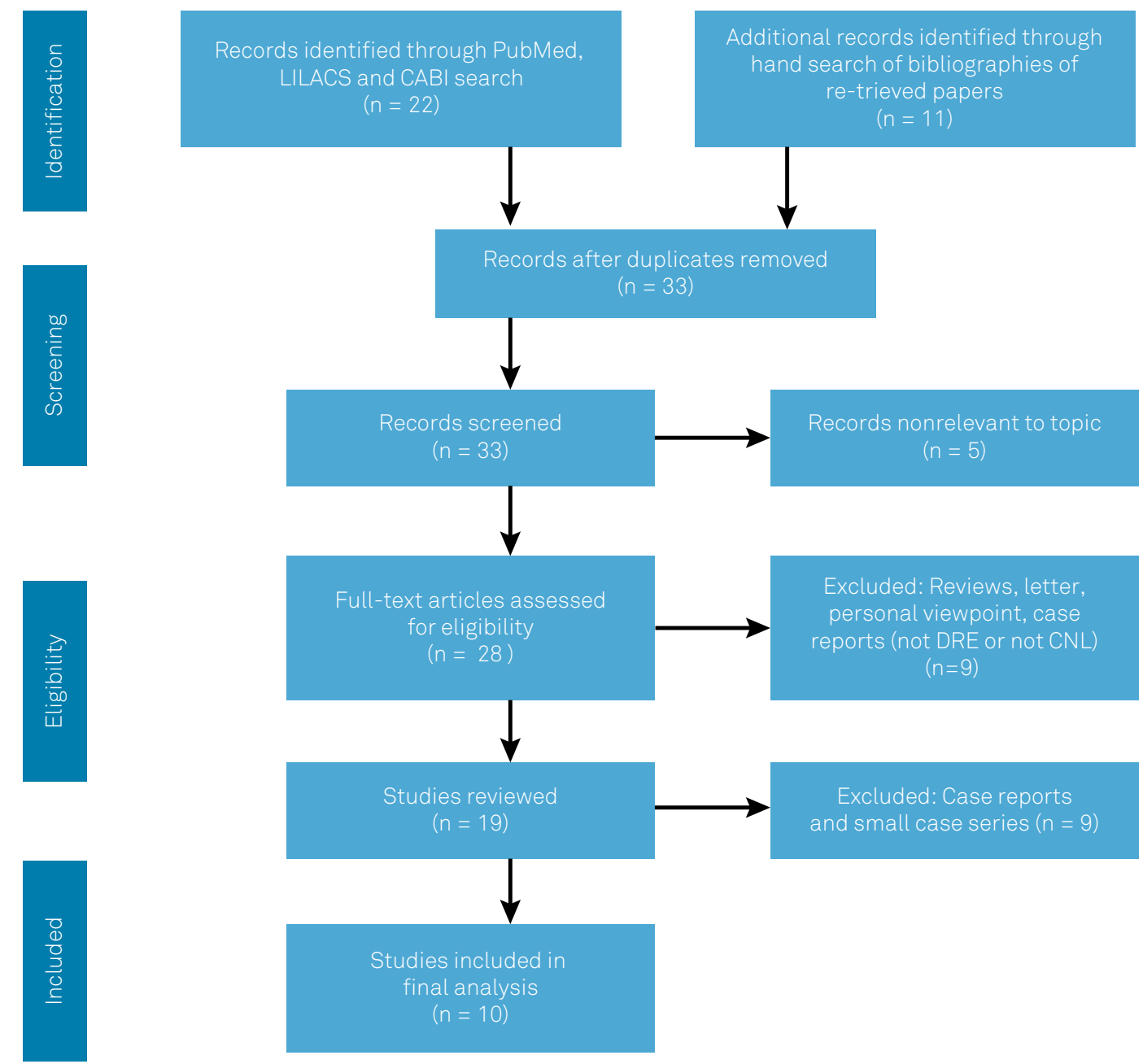

Note: 1. Search terms: ("Neurocysticercosis"[Mesh] OR Cysticercosis[TW]) AND (“mesial temporal sclerosis"[TW] OR “hippocampal sclerosis"[TW]); 2. Refer to Table 1 for classification of the reports included in the review.

Figure 1. Study results.

those with HS alone ${ }^{11,29}$, a finding not corroborated by still others $^{31}$. An Indian study noted that while roughly a fifth of individuals with HS with CNLs had childhood febrile seizures, nearly another half reported afebrile seizures in the first decade of life ${ }^{29}$.

An earlier Brazilian study found no difference in the proportion of those with unilateral versus bitemporal spikes but a subsequent re-analysis from the same center with more cases, as well as another Indian study, noted that the finding of bitemporal spikes correlated with the presence of CNL in individuals with $\mathrm{HS}^{15,29,32}$.

\section{Number and laterality of CNL and HS}

Within CNL-HS groups in published reports, the proportion of solitary calcification varied from $25 \%$ to $67 \%^{11,28,29,30,31}$. The case series from India had the highest proportion of solitary calcifications ${ }^{11,29}$. Overall, $21-83 \%$ of the calcifications (regardless of whether they were solitary or multiple) ) $^{11,15,31}$ and $85-100 \%$ of solitary calcifications ${ }^{11,28,29,30}$ were found exclusively ipsilateral to the diseased hippocampus. Four studies reported the lobar location of the CNLs and in these reports the frequency of ipsilateral temporal lobe CNLs varied between $9 \%$ and $67 \%{ }^{11,15,28,31}$ In some cases, varying from $3 \%$ to $33 \%$, the CNL was located within or in close proximity to the hippocampus (Figure 2 a-d). ${ }^{11,12,15,28}$

\section{Choice of surgical approach and postsurgical outcome}

One small report of four cases, on whom a standard temporal lobectomy was performed, reported seizure freedom in only one individual with CNL-HS. ${ }^{11}$ In comparison, an Engel Class I outcome was reported in nearly three quarters of a cohort of 126 people on whom standard temporal lobectomy was performed ${ }^{27}$ (Table 3 ). A lesionectomy alone was performed on seven people and postoperative seizure freedom documented in four. ${ }^{11,23}$ In one of these cases, who continued to have seizures after lesionectomy, the seizures were related to new parenchymal cysticerci emerging after surgery ${ }^{24}$ Only three individuals with an extratemporal CNL and HS evaluated with invasive EEG were reported; all had seizure onsets from the CNL as well as the hippocampus and were seizure-free following standard temporal lobectomy 
Table 1. Classification of published reports [excluding case reports and small $(n=\langle 5)$ series] retrieved for this review.

\begin{tabular}{|c|c|c|c|c|}
\hline Variable & Author, year & Study design & Study location & Comment \\
\hline \multirow{4}{*}{$\begin{array}{l}\text { Studies of association } \\
\text { between HS and CNL }\end{array}$} & Velasco et al., $2006^{16}$ & $\begin{array}{l}\text { Hospital-based } \\
\text { cross-sectional study }\end{array}$ & $\begin{array}{l}\text { Sao Paulo, Brazil, } \\
\text { Referral centre for } \\
\text { epilepsy surgery }\end{array}$ & $\begin{array}{c}\text { Compared prevalence of CNLs } \\
\text { among patients with HS with } \\
\text { other etiologies of epilepsy }\end{array}$ \\
\hline & Oliveira et al., $2014^{31}$ & $\begin{array}{l}\text { Hospital-based } \\
\text { cross-sectional study }\end{array}$ & $\begin{array}{l}\text { Sao Paulo, Epilepsy } \\
\text { clinic-based }\end{array}$ & $\begin{array}{c}\text { Compared prevalence of CNLs } \\
\text { among patients with HS with } \\
\text { other etiologies of epilepsy }\end{array}$ \\
\hline & Taveira et al., $2015^{30}$ & $\begin{array}{l}\text { Case control study, } \\
\text { hospital-based }\end{array}$ & $\begin{array}{l}\text { Sao Paulo, Referral } \\
\text { centre for epilepsy } \\
\text { surgery }\end{array}$ & $\begin{array}{l}\text { Compared prevalence of CNLs } \\
\text { among s patients with HS with } \\
\text { other etiologies of epilepsy }\end{array}$ \\
\hline & $\begin{array}{l}\text { Del Brutto et al., } 2015^{35} \\
\text { Del Brutto et al., } 2017^{36}\end{array}$ & $\begin{array}{l}\text { Population-based, } \\
\text { exposed-unexposed } \\
\text { study }\end{array}$ & Ecuador & $\begin{array}{c}\text { Determined prevalence ratio of } \\
\text { hippocampal atrophy among } \\
\text { patients with CNLs with those } \\
\text { with no evidence of NCC }\end{array}$ \\
\hline \multirow{5}{*}{$\begin{array}{l}\text { Studies comparing } \\
\text { demographic features } \\
\text { of CNL-HS with HS } \\
\text { alone }\end{array}$} & *Bianchin et al., $2015^{28}$ & & & \\
\hline & Bianchin et al., $2013^{27}$ & Hospital-based series & Sao Paulo, Brazil & \\
\hline & Leite et al., 200015 & & & \\
\hline & Rathore et al., $2012^{29}$ & & & \\
\hline & & Hospital-based series & Trivandrum, India & \\
\hline \multirow{2}{*}{$\begin{array}{l}\text { Studies describing } \\
\text { surgical outcome in } \\
\text { CNL-HS/CNL alone }\end{array}$} & $\begin{array}{l}\text { Bianchin et al., } 2013^{27} \\
\text { Leite et al., } 2000^{15}\end{array}$ & Hospital-based series & Sao Paulo, Brazil & \\
\hline & Rathore et al., $2013^{11}$ & Hospital-based series & Trivandrum, India & \\
\hline
\end{tabular}

${ }^{*}$ The studies listed in this cell were published at different periods of time from the same center and comprised overlapping sets of
reports with the largest number ${ }^{27,28}$ were used for analysis. Case reports and small series of cases are not represented in this table.

Table 2. Comparison of demographic and electroclinical features of CNL-HS and HS alone.

\begin{tabular}{|c|c|c|}
\hline Author, year & HS alone & CNL-HS \\
\hline \multicolumn{3}{|c|}{ Age of onset (First unprovoked seizure) (mean SD) } \\
\hline Rathore et al., $2012^{29}$ & $10 \pm 6$ years & $16 \pm 7$ years \\
\hline Bianchin et al., $2013^{27}$ & $9 \pm 9$ years & $10 \pm 8$ years \\
\hline \multicolumn{3}{|c|}{ Gender distribution (Proportion of femal.es) } \\
\hline Bianchin et al., $2013^{27}$ & $54 \%$ & $62 \%$ \\
\hline Oliveira et al., $2015^{31}$ & $70 \%$ & $67 \%$ \\
\hline \multicolumn{3}{|c|}{$\begin{array}{l}\text { Antecedent febrile seizures (initial. precipitating illness) } \\
\text { \{Proportion; (\%)\} }\end{array}$} \\
\hline Chandra et al., $2010^{12}$ & & Nil \\
\hline Rathore et al., $2012^{29}$ & $53 \%$ & $22 \%$ \\
\hline Oliveira et al., $2015^{31}$ & $23 \%$ & $27 \%$ \\
\hline \multicolumn{3}{|c|}{ Proportion of bitemporal. spikes(\%) } \\
\hline Leite et al., $2000^{15}$ & $10 \%$ & $11 \%$ \\
\hline Rathore et al., $2012^{29}$ & $8 \%$ & $50 \%$ \\
\hline
\end{tabular}

with lesionectomy (excision of the CNL). ${ }^{11,16}$ Lastly, a subset comprising people in whom the CNL was located within or in close proximity to the hippocampus, including the parahippocampal and fusiform gyri, the insula and the temporal pole (3-33\% of all operated cases with HS and CNL) was put together ${ }^{11,12,15,20}$. All were seizure-free following temporal resections, which included the CNL.

\section{DISCUSSION}

\section{Is there an association between NCC and HS?}

A growing number of reports supports the plausibility of an association between NCC and HS $10,11,15,16,19-29,31$. The small numbers of participants in most studies, variations in methods used and outcomes assessments, however, limit the application of quantitative meta-analytic approaches to clarify the association. Additionally, the available reports are either retrospective or cross-sectional studies, mostly originating from specialized centers in São Paulo, Brazil, thereby introducing a potential referral bias, which could confound the interpretation ${ }^{16,30,31}$. Several studies have compared the frequency of CNLs on CT scans between groups with HS and other epilepsies ${ }^{16,30,31}$. One compared the frequency of CNLs in people with HS with those with headache ${ }^{30}$. The comparator groups (i.e., epilepsies other than those with HS and headache) are not ideal as there are documented associations between CNLs and epilepsy and headache in T. solium cysticercosis-endemic areas ${ }^{33,34}$. It might be pertinent to compare the frequency of CNLs in mesial temporal lobe epilepsy associated with HS with other temporal lobe epilepsies and extratemporal lobe epilepsies but this does not seem to 

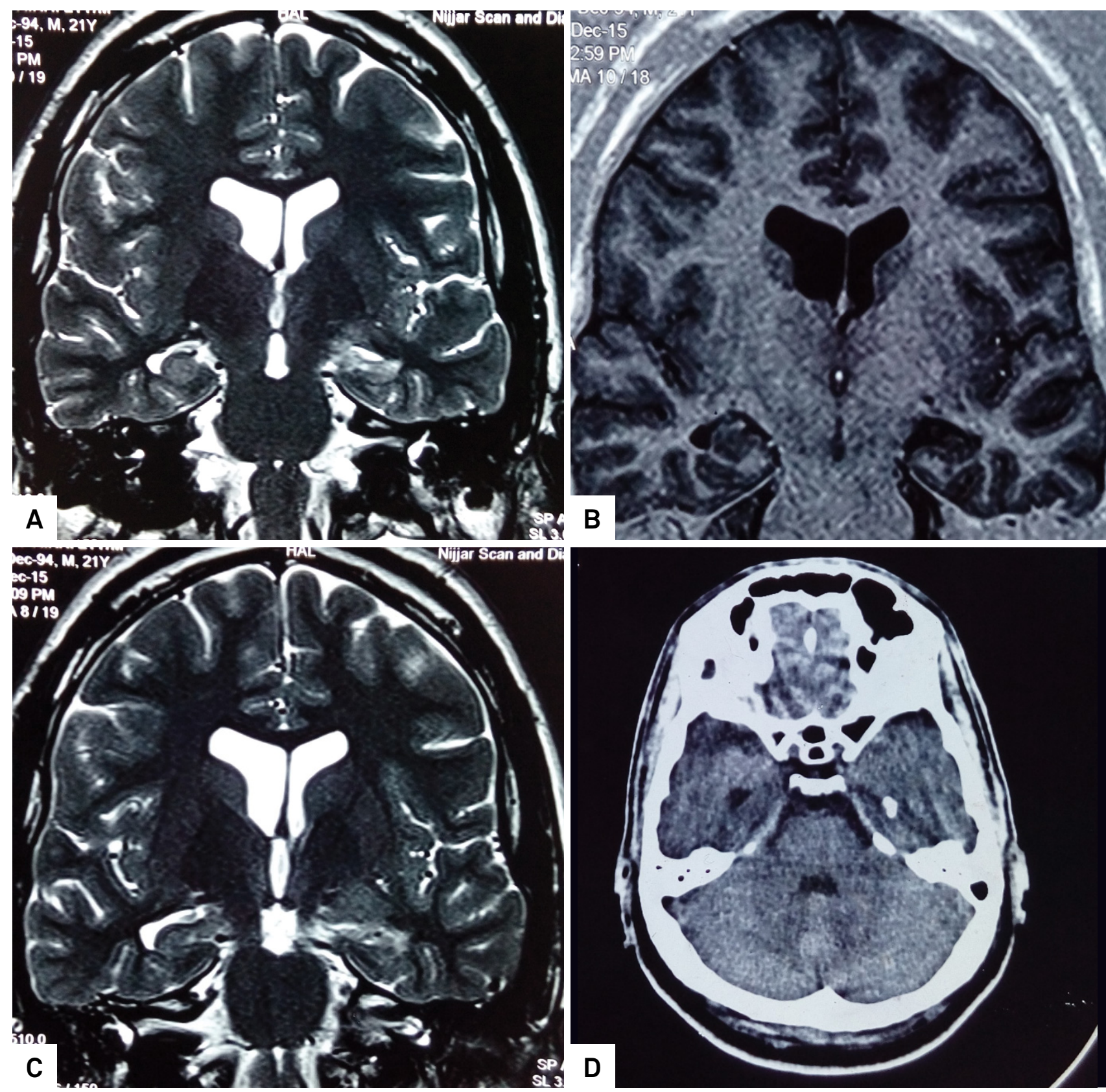

Figure 2. Hippocampal sclerosis with a spatially-proximated CNL. Note (a) T2 oblique coronal image showing left HS, (b) T1 oblique coronal image demonstrating left hippocampal atrophy, (c) T2 oblique coronal image showing proximate CNL (arrow) with surrounding hyperintensity presumed to be gliosis and (d) axial computed tomography image clearly demonstrating the left temporal CNL.

Table 3. Surgical procedures and outcomes following surgery for drug-resistant epilepsy in people with CNLs with or without HS.

\begin{tabular}{|c|c|c|c|}
\hline Surgical procedure & Reference (Author, year) & $\begin{array}{c}\text { Number of cases } \\
\text { operated on }\end{array}$ & $\begin{array}{c}\text { Number of cases with } \\
\text { postoperative seizure } \\
\text { freedom }\end{array}$ \\
\hline \multirow{3}{*}{$\begin{array}{l}\text { Standard anteromesial temporal } \\
\text { lobectomy (with/without CNL in the } \\
\text { surgical field) }\end{array}$} & Rathore et al., $2013^{11}$ & 7 & $4(57 \%)$ \\
\hline & Leite et al., $2000^{15}$ & 32 & $26(81 \%)$ \\
\hline & Bianchin et al., $2013^{27}$ & 126 & $94(75 \%)$ \\
\hline \multirow{2}{*}{ Lesionectomy alone } & Ooi et al., $2011^{23}$ & 1 & 0 \\
\hline & Rathore et al., $2013^{11}$ & $6^{\#}$ & 4 \\
\hline $\begin{array}{l}\text { Anteromesial temporal lobectomy with } \\
\text { resection of extratemporal CNL }\end{array}$ & Rathore et al., $2013^{11}$ & 2 & 2 \\
\hline
\end{tabular}

Including one case with HS and five with no imaging evidence of HS (Ref. 11). 
have been undertaken. The association should also be examined in a population-based sample, a major undertaking in resource-limited settings. A single, small population-based survey in Ecuador evaluated the association between CNLs and hippocampal atrophy, suggesting that CNLs or their precursors, i.e., active NCC or associated seizures, might be causally associated with hippocampal injury ${ }^{35}$. The majority of participants, however, did not have epilepsy, a defining feature of HS. When stratified according to age, the association became significant only in those aged above 68 years $^{36}$. This age-specific association is in marked contrast to the usual much younger age of onset of typical $\mathrm{HS}^{37-39}$. Sclerosis of the hippocampus on T2 or FLAIR MR images, crucial to the recognition of HS, was also not reported.

\section{Demographic and electroclinical characteristics of CNL-HS}

It might be argued that, if indeed there were a causal association between CNLs and HS, the CNLs might modify some of the demographic, electroclinical and prognostic characteristics of HS. Among various demographic attributes, a gender predilection has been reported from a single Brazilian center with an excess of women among people with CNL-HS ${ }^{15,26}$. Gender-related differences in host inflammatory responses to cysticerci have been suggested as the basis for this observation. ${ }^{40}$ The findings of a gender predilection have not been replicated in a report from a different center in Brazil, nor in India ${ }^{29,31}$. There is also no documented gender predilection for HS alone as no differences have been reported in large HS series ${ }^{37,38,39}$. Other demographic features, e.g., age of onset of habitual seizures, in CNL-HS appear to be similar to HS alone, usually in the first two decades of life. Some reports also covered the frequency of an antecedent initial precipitating illness in people with CNL-HS ${ }^{11,12,16,29}$. Febrile seizures have been reported in $82 \%$ of people with HS alone ${ }^{37,39}$, while antecedent, early life afebrile seizures are extremely rare. There have been reports of a lower frequency, or even complete absence, of antecedent febrile seizures in people with CNL-HS ${ }^{12,29,32}$. Conversely, afebrile seizures in the first decade of life, reported with a high frequency (44\%) in people with CNL-HS from India may represent acute seizures related to active parenchymal $\mathrm{NCC}^{29}$. It is also possible that the lower frequencies of febrile seizures may partly be accounted for by a recall bias. More studies from different geographical locations are clearly desirable to clarify the gender predilection as well as other possible distinctive features of CNL-HS, if any.

\section{Location and laterality of CNLs in relation to HS}

We surmise that causality is more likely if the CNL is located ipsilateral to the side of HS and within the ipsilateral hemisphere, in proximity to the hippocampus. The likelihood of publication bias should be taken in to account in interpreting published data regarding the location of the CNLs. Besides, the analysis of the laterality and location of CNLs in relation to HS is complicated by the multiplicity of CNLs with distribution across both hemispheres, making it difficult to decide which of the lesions is the culprit; in some reports a large proportion of the CNLs are multiple. ${ }^{15,28}$ In comparison, a solitary CNL offers the opportunity of analyzing the laterality and lobar (or sublobar) location of the CNL in relation to the HS. Overall, the majority (roughly three quarters) of the reported solitary CNLs are located ipsilateral to the HS. . $1,15,28,31^{-1}$ In a number of isolated case reports and in some of the larger series, the CNL may be located within, or in close proximity to, the hippocampus followed by the ipsilateral temporal lobe. ${ }^{11,12,15,20}$ This seems to suggest that the proximity of the CNL to the hippocampus and related structures might be a factor in the development of HS. It is plausible that an inflammatory response to the CNL engenders an insult to the proximate hippocampus, thereby provoking a cascade of events eventually leading to the development of HS.

\section{Is the association causal?}

Even as an association between NCC and HS is plausible, we need to consider whether the association is causal. ${ }^{41} \mathrm{To}$ infer causality, more studies in different geographic regions, endemic and nonendemic, are required to gauge the strength and consistency of the association. Support for a biological gradient in the association is provided by the predilection of solitary CNLs distributed ipsilaterally and within the same hemisphere, in proximate locations to the diseased hippocampus. These findings may be implicit with the argument that acutely degenerating cysticercus or associated seizures might constitute the initial precipitating illness for HS. It is also desirable to conduct experiments in animal models with, for example, cysticercus extracts injected into different locations in the cerebral hemispheres, to determine the effect on hippocampal structure and function. ${ }^{42}$

\section{Choice of surgical approach}

An assessment of seizure outcome following surgery is precluded by the limited number of reports, varied use of presurgical evaluation strategies and time periods and methods of outcome assessment. It appears, however, that surgical outcome following standard temporal lobe procedures in terms of seizure freedom in CNL-HS is similar to HS alone. ${ }^{15,16,27}$ Surgical failure with standard anteromesial temporal lobectomy following noninvasive presurgical workup has also been anecdotally documented, implying that no one-fits-all approach can be recommended. ${ }^{11}$ Other approaches, including lesionectomy (removal of CNL alone) and combined approaches (i.e., lesionectomy in addition to the temporal lobectomy; $c f$, dual pathology) have been employed in the surgical management of drugresistant epilepsy associated with CNL-HS. ${ }^{11}$ It is reasonable to recommend that the surgical approach should be tailored to the situation and the results of presurgical workup. If dual pathology, in terms of independent seizure 
origins from the hippocampus and CNL, is suspected during noninvasive presurgical workup, then recourse to invasive monitoring appears appropriate and justified despite limitations of cost and availability in regions where NCC is endemic. In situations where the CNL is located close to the hippocampal structures, it is reasonable to excise the lesion along with other temporal lobe structures. Since different clinical scenarios exist, a case-by-case approach should be followed in evaluating and managing people with CNL-HS. Indeed, the categorization of CNLs in association with HS described in a recent review compliments the approach presented here. ${ }^{43}$

\section{Future directions}

If CNLs and HS were causally associated, the underlying basis might be an interaction between the cysticercus granuloma and the hippocampus structure and function or an effect mediated through kindling by repeated seizures. The fact that CNLs can be found on imaging studies in as many as $10-18 \%$ of asymptomatic individuals in T. solium-endemic communities ${ }^{44,45}$ might be utilized in dissecting out a direct effect of cysticercus granulomas versus an effect mediated through seizures, and it might be worthwhile to study the prevalence of hippocampal abnormalities in people with asymptomatic CNLs.

The association between NCC and HS merits further investigation as it has far-reaching implications for understanding not only the burden and etiology of epilepsies in resource-poor countries but also, overall, the phenomenon of epileptogenesis.

\section{CONCLUSIONS}

The available evidence is at best hypothesis-generating, providing preliminary support for an association between CNLs and HS. The association should be investigated further in population-based samples to avoid selection bias. Prospective, longitudinal follow-up imaging studies of the hippocampal structure and volume in people presenting with a first seizure associated with NCC are desirable. The longitudinal design would help in establishing temporality between cause (NCC infestation) and effect (HS). Future studies should also be located in geographically disparate $T$. solium-endemic regions.

\section{ACKNOWLEDGMENTS}

This work was done at the NIHR University College London Hospitals Biomedical Research Centre, which receives a proportion of funding from the UK Department of Health's Comprehensive Biomedical Research Centers funding scheme. JWS receives support from the Dr. Marvin Weil Epilepsy Research Fund and the UK Epilepsy Society. We are grateful to Dr. Gail S. Bell for thoroughly reviewing the manuscript.

\section{References}

1. Del Brutto OH. Neurocysticercosis: a review. Sci World J. 2012;2012:159821. https://doi.org/10.1100/2012/159821

2. World Health Organization. Taenaisis/cysticercosis: fact sheet. Geneve: World Health Organization; 2017 [cited 2017 May 3]. Available from: http://www.who.int/mediacentre/factsheets/ fs376/en/

3. Montano SM, Villaran MV, Ylquimiche L, Figueroa JJ, Rodriguez S, Bautista CT et al. Neurocysticercosis: association between seizures, serology, and brain CT in rural Peru. Neurology. 2005 Jul;65(2):229-33. https://doi.org/10.1212/01.wnl.0000168828.83461.09

4. Medina MT, Aguilar-Estrada RL, Alvarez A, Durón RM, Martínez L, Dubón S et al. Reduction in rate of epilepsy from neurocysticercosis by community interventions: the Salamá, Honduras study. Epilepsia. 2011 Jun;52(6):1177-85. https://doi.org/10.1111/j.1528-1167.2010.02945.x

5. Singh G, Bawa J, Chinna D, Chaudhary A, Saggar K, Modi M et al. Association between epilepsy and cysticercosis and toxocariasis: a population-based case-control study in a slum in India. Epilepsia. 2012 Dec;53(12):2203-8. https://doi.org/10.1111/epi.12005

6. Rajshekhar V, Raghava MV, Prabhakaran V, Oommen A, Muliyil J. Active epilepsy as an index of burden of neurocysticercosis in Vellore district, India. Neurology. 2006 Dec;67(12):2135-9. https://doi.org/10.1212/01.wnl.0000249113.11824.64

7. Carabin H, Ndimubanzi PC, Budke CM, Nguyen H, Qian Y, Cowan LD et al. Clinical manifestations associated with neurocysticercosis: a systematic review. PLoS Negl Trop Dis. 2011 May;5(5):e1152. https://doi.org/10.1371/journal.pntd.0001152
8. Carpio A, Hauser WA. Prognosis for seizure recurrence in patients with newly diagnosed neurocysticercosis. Neurology. 2002 Dec;59(11):1730-4. https://doi.org/10.1212/01.WNL.0000036320.69823.EA

9. Del Brutto OH, Santibañez R, Noboa CA, Aguirre R, Díaz E, Alarcón TA. Epilepsy due to neurocysticercosis: analysis of 203 patients. Neurology. 1992 Feb;42(2):389-92. https://doi.org/10.1212/WNL.42.2.389

10. Singla M, Singh P, Kaushal S, Bansal R, Singh G. Hippocampal sclerosis in association with neurocysticercosis. Epileptic Disord. 2007 Sep;9(3):292-9. https://doi.org/10.1684/epd.2007.0122

11. Rathore C, Thomas B, Kesavadas C, Abraham M, Radhakrishnan K. Calcified neurocysticercosis lesions and antiepileptic drug-resistant epilepsy: a surgically remediable syndrome? Epilepsia. 2013 Oct;54(10):1815-22. https://doi.org/10.1111/epi.12349

12. Chandra PS, Bal C, Garg A, Gaikwad S, Prasad K, Sharma BS et al. Surgery for medically intractable epilepsy due to postinfectious etiologies. Epilepsia. 2010 Jun;51(6):1097-100. https://doi.org/10.1111/j.1528-1167.2010.02538.x

13. Pradhan S, Kathuria MK, Gupta RK. Perilesional gliosis and seizure outcome: a study based on magnetization transfer magnetic resonance imaging in patients with neurocysticercosis. Ann Neurol. 2000 Aug;48(2):181-7. https://doi.org/10.1002/1531-8249(200008)48:2<181::AID-ANA7 $>3.0 . \mathrm{CO} ; 2-\mathrm{C}$ 
14. de Souza A, Nalini A, Kovoor JM, Yeshraj G, Siddalingaiah HS, Thennarasu K. Perilesional gliosis around solitary cerebral parenchymal cysticerci and long-term seizure outcome: a prospective study using serial magnetization transfer imaging. Epilepsia. 2011 Oct;52(10):1918-27. https://doi.org/10.1111/j.1528-1167.2011.03189.x

15. Leite JP, Terra-Bustamante VC, Fernandes RM, Santos AC, Chimelli $L$, Sakamoto AC et al. Calcified neurocysticercotic lesions and postsurgery seizure control in temporal lobe epilepsy. Neurology. 2000 Nov;55(10):1485-91. https://doi.org/10.1212/WNL.55.10.1485

16. Velasco TR, Zanello PA, Dalmagro CL, Araújo D Jr, Santos AC, Bianchin MM et al. Calcified cysticercotic lesions and intractable epilepsy: a cross sectional study of 512 patients. J Neurol Neurosurg Psychiatry. 2006 Apr;77(4):485-8. https://doi.org/10.1136/jnnp.2005.078675

17. Singh G, Burneo JG, Sander JW. From seizures to epilepsy and its substrates: neurocysticercosis. Epilepsia. 2013 May;54(5):783-92. https://doi.org/10.1111/epi.12159

18. Durnford AJ, Rodgers W, Kirkham FJ, Mullee MA, Whitney A, Prevett $M$ et al. Very good inter-rater reliability of Engel and ILAE epilepsy surgery outcome classifications in a series of 76 patients. Seizure. 2011 Dec;20(10):809-12. https://doi.org/10.1016/j.seizure.2011.08.004

19. Kobayashi E, Guerreiro CA, Cendes F. Late onset temporal lobe epilepsy with MRI evidence of mesial temporal sclerosis following acute neurocysticercosis: case report. Arq Neuropsiquiatr. 2001 Jun;59 2-A:255-8. https://doi.org/10.1590/S0004-282X2001000200021

20. Chung CK, Lee SK, Chi JG. Temporal lobe epilepsy caused by intrahippocampal calcified cysticercus: a case report. J Korean Med Sci. 1998 Aug;13(4):445-8. https://doi.org/10.3346/jkms.1998.13.4.445

21. Silva AV, Martins HH, Marques CM, Yacubian EM, Sakamoto AC, Carrete Junior $\mathrm{H}$ et al. Neurocysticercosis and microscopic hippocampal dysplasia in a patient with refractory mesial temporal lobe epilepsy. Arq Neuropsiquiatr. 2006 Jun;64(2A):309-13. https://doi.org/10.1590/S0004-282X2006000200026

22. Son El, Yi SD, Lee SW, Lee HC, Yim MB, Kim IH. Surgery for seizurerelated structural lesions of the brain with intraoperative acute recording(ECoG) and functional mapping. J Korean Med Sci. 1994 Oct;9(5):409-13. https://doi.org/10.3346/jkms.1994.9.5.409

23. Ooi WW, Wijemanne S, Thomas CB, Quezado M, Brown CR, Nash TE. Short report: A calcified Taenia solium granuloma associated with recurrent perilesional edema causing refractory seizures: histopathological features. Am J Trop Med Hyg. 2011 Sep;85(3):4603. https://doi.org/10.4269/ajtmh.2011.11-0221

24. Lee DJ, Owen CM, Khanifar E, Kim RC, Binder DK. Isolated amygdala neurocysticercosis in a patient presenting with déjà vu and olfactory auras. Case report. J Neurosurg Pediatr. 2009 Jun;3(6):538-41. https://doi.org/10.3171/2009.2.PEDS08140

25. Hasan MS, Basri HB, Hin LP, Stanslas J. Surgical remotion of a cysticercotic granuloma responsible for refractory seizures: A case report. Surg Neurol Int. 2011;2(1):177-9. https://doi.org/10.4103/2152-7806.90698

26. da Gama CN, Kobayashi E, Li LM, Cendes F. Hippocampal atrophy and neurocysticercosis calcifications. Seizure. 2005 Mar;14(2):85-8. https://doi.org/10.1016/j.seizure.2004.10.005

27. Bianchin MM, Velasco TR, Coimbra ER, Gargaro AC, Escorsi-Rosset SR, Wichert-Ana L et al. Cognitive and surgical outcome in mesial temporal lobe epilepsy associated with hippocampal sclerosis plus neurocysticercosis: a cohort study. PLoS One. 2013 Apr;8(4):e60949. https://doi.org/10.1371/journal.pone.0060949

28. Bianchin MM, Velasco TR, Wichert-Ana L, Araújo Junior D, Alexandre Junior V, Scornavacca F et al. Neuroimaging observations linking neurocysticercosis and mesial temporal lobe epilepsy with hippocampal sclerosis. Epilepsy Res. 2015 Oct;116:34-9. https://doi.org/10.1016/j.eplepsyres.2015.07.001
29. Rathore C, Thomas B, Kesavadas C, Radhakrishnan K. Calcified neurocysticercosis lesions and hippocampal sclerosis: potential dual pathology? Epilepsia. 2012 Apr;53(4):e60-2. https://doi.org/10.1111/j.1528-1167.2011.03386.x

30. Taveira MO, Morita ME, Yasuda CL, Coan AC, Secolin R, Costs ALC et al. Neurocysticercotic calcifications and hippocampal sclerosis: A case-control study. PLoS One. 2015;10: https://doi.org/10.1371/journal.pone.0131180

31. Oliveira MC, Martin MG, Tsunemi MH, Vieira G, Castro LH. Small calcified lesions suggestive of neurocysticercosis are associated with mesial temporal sclerosis. Arq Neuropsiquiatr. 2014 Jul;72(7):510-6. https://doi.org/10.1590/0004-282X20140080

32. Bianchin MM, Velasco TR, Araujo Junior D, Alexandre V Jr, WichertAna L, Vera $\mathrm{C}$ et al. Clinical and electrophysiological differences between mesial temporal lobe epilepsy and mesial temporal lobe epilepsy plus neurocysticercosis [Abstract]. Epilepsia. 2006;4 suppl 4:244-5.

33. Cruz ME, Cruz I, Preux PM, Schantz P, Dumas M. Headache and cysticercosis in Ecuador, South America. Headache. 1995 Feb;35(2):937. https://doi.org/10.1111/j.1526-4610.1995.hed3502093.x

34. Garg RK, Kar AM, Singh MK. Prednisolone-responsive headache in patients with solitary cysticercus granuloma and seizures. Headache. 2004 Apr;44(4):365-9. https://doi.org/10.1111/j.1526-4610.2004.04096.x

35. Del Brutto OH, Salgado P, Lama J, Del Brutto VJ, Campos X, Zambrano $M$ et al. Calcified neurocysticercosis associates with hippocampal atrophy: a population-based study. Am J Trop Med Hyg. 2015 Jan;92(1):64-8. https://doi.org/10.4269/ajtmh.14-0453

36. Del Brutto OH, Issa NP, Salgado P, Del Brutto VJ, Zambrano M, Lama J et al. The association between neurocysticercosis and hippocampal atropy is related to age. Am J Trop Med Hyg. 2017 Jan;96(1):243-8. https://doi.org/10.4269/ajtmh.16-0689

37. Cendes F, Andermann F, Dubeau F, Gloor P, Evans A, Jones-Gotman $M$, et al. Early childhood prolonged febrile convulsions, atrophy and sclerosis of mesial structures, and temporal lobe epilepsy: an MRI volumetric study. Neurology. 1993 Jun;43(6):1083-7. https://doi.org/10.1212/WNL.43.6.1083

38. Cendes F. Febrile seizures and mesial temporal sclerosis. Curr Opin Neurol. 2004 Apr;17(2):161-4. https://doi.org/10.1097/00019052-200404000-00013

39. French JA, Williamson PD, Thadani VM, Darcey TM, Mattson RH, Spencer SS, et al. Characteristics of medial temporal lobe epilepsy: I. Results of history and physical examination. Ann Neurol. 1993 Dec;34(6):774-80. https://doi.org/10.1002/ana.410340604

40. Rangel R, Torres B, Del Bruto O, Sotelo J. Cysticercotic encephalitis: a severe form in young females. Am J Trop Med Hyg. 1987 Mar;36(2):387-92. https://doi.org/10.4269/ajtmh.1987.36.387

41. Höfler M. The Bradford Hill considerations on causality: a counterfactual perspective. Emerg Themes Epidemiol. 2005 Nov;2(1):11. https://doi.org/10.1186/1742-7622-2-11

42. Stringer JL, Marks LM, White AC Jr, Robinson P. Epileptogenic activity of granulomas associated with murine cysticercosis. Exp Neurol. 2003 Oct;183(2):532-6. https://doi.org/10.1016/S0014-4886(03)00179-1

43. Escalaya AL, Burneo JG. Epilepsy surgery and neurocysticercosis: assessing the role of the cysticercotic lesion in medicallyrefractory epilepsy. Epilepsy Behav. 2017 Nov;76:178-81. https://doi.org/10.1016/j.yebeh.2017.01.029

44. Cruz ME, Schantz PM, Cruz I, Espinosa P, Preux PM, Cruz A et al. Epilepsy and neurocysticercosis in an Andean community. Int J Epidemiol. 1999 Aug;28(4):799-803. https://doi.org/10.1093/ije/28.4.799

45. Fleury A, Gomez T, Alvarez I, Meza D, Huerta M, Chavarria A et al. High prevalence of calcified silent neurocysticercosis in a rural village of Mexico. Neuroepidemiology. 2003 Mar-Apr;22(2):139-45. https://doi.org/10.1159/000068748 